\title{
Health Services Management Education On-Site At A Military Medical Center
}

\author{
Stephen J. Williams, San Diego State University, USA \\ W. Bradley Poss, University of Utah School of Medicine, USA \\ Craig L. Cupp, Franciscan Ear, Nose \& Throat Associates at St. Joseph, USA
}

\begin{abstract}
A cooperative educational program with the U.S. military is described to illustrate a unique opportunity that confronted a graduate healthcare management program. The resulting degree program supported the military's operational medical mission but also presented interesting and unexpected challenges resulting from the wars in Iraq and Afghanistan. Pressure to provide costeffective services has been mounting for many years. Civilian and military cooperative ventures can be highly successful. The program addressed the need for enhanced managerial skills. Program content focused on traditional business and healthcare content with applications tailored to military settings. While instruction was provided primarily by civilian faculty, active duty military instructors were also incorporated into specific course content areas. Program pricing and marketing were critical to success. Technical course delivery issues raised additional challenges due to work obligations and deployments. Academic institutions need to assist military commands in achieving their training objectives and can benefit from the experience.
\end{abstract}

The views expressed in this article are those of the authors and do not reflect the official policy or position of the Department of the Navy, Department of Defense, or the United States Government.

Keywords: Military; Management Education; Education Innovations

\section{INTRODUCTION}

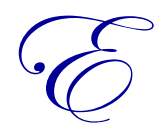

mphasis on managerial skills development has increased at U.S. military medical facilities as demands for leadership, improved quantity and complexity of care, accountability of resource use, and workload efficiency have increased (Chaffee \& Mill, 2001; Sentell \& Finstuen, 1998). Seeking to enhance training of medical staff and senior administrators, a large Naval Medical Center (NMC) collaborated with a local university in offering a master's degree program in health services management. This experience and the lessons learned in pursuing such an endeavor are described here.

Navy medicine supports the military mission. In addition, it seeks to ensure that active-duty families and retirees receive the medical care that they need. Readiness is an extremely important component of operations. Responsibility to the American public for assuring that resources are used appropriately and efficiently is also considered a priority. Strategic missions are achieved at least in part by the optimal use of medical information systems technology and excellent business processes. Quality of care, as well as efficiency of operations, are important. Providing value is a mantra (U.S Navy Medicine, 2013).

Military medicine is under pressure to control rising healthcare costs. As a result, department heads and division officers must be able to demonstrate sound business practices; by their own admission, many NMC department heads have lacked required healthcare management skills.

Medical Service and Nursing Corps officers have several opportunities for obtaining healthcare management degrees. Each corps has funded a core group of individuals for advanced training and many have chosen healthcare leadership programs in addition to nursing research and nurse practitioner programs. In contrast, 
the Medical and Dental Corps have primarily used their training funds for residencies and fellowships to ensure that proper medical and dental specialists are available for operational and Military Treatment Facilities' (MTFs) healthcare needs as well as to support in-house Graduate Medical Education (GME) training programs. The Medical Corps has funded relatively few individuals for MBAs or similar programs, thus providing limited opportunities for medical and dental corps officers to obtain healthcare leadership and business degrees despite a growing interest and need.

Naval Medical Center, San Diego (NMCSD) traces its origins to a tent dispensary established in Balboa Park in 1914 (Christman, 1985). The first true hospital opened in 1922. At the peak of World War II, approximately 5,000 patients were admitted each month. A major expansion of the physical plant opened in 1988. The hospital is now a 272 bed multispecialty and ambulatory care facility. The hospital has provided personnel for deployment to the Middle East war fronts. The hospital ship Mercy is also supported. The hospital is a major training facility for clinical medicine and other fields. The hospital employs approximately 6,500 personnel, of whom nearly one third are civilian employees or contractors. Many of the civilian employees are in supervisory and management positions, but opportunities to obtain funded healthcare management degrees are limited. The role of civilian managers becomes even more prominent when military to civilian position conversions occur. The medical staff includes 400 physicians and the medical training programs comprise approximately 400 interns, residents, and fellows. Approximately 4,000 outpatient visits and 45 admissions occur daily (NMCSD, 2013).

To address these training needs, senior medical staff at NMCSD approached the Division of Health Services Administration, seeking to jointly develop a cost effective degree program in healthcare management. The Division's 34-unit Master of Public Health (MPH) program, designed for individuals with considerable prior experience, was selected by the Navy for on-base availability and joint sponsorship. This program had been offered on site at the University for a number of years, but has now been phased out due to the implementation of new Council on Education for Public Health (CEPH) mandated minimum unit requirements for MPH degrees.

To help support participation in the program, NMCSD created a Civilian Tuition Assistance Program and funded it at $\$ 37,500$ per year, allowing up to 10 civilian employee students to obtain $\$ 3,750$ in tuition assistance per year $(\$ 7,500$ total for the 2-year program). Students who signed up for the program were expected to continue their employment with NMCSD for 2 years after completion of the program or repayment was required. Potential civilian employee students were to be identified and nominated by their respective clinical directors.

\section{PROGRAM CONTENT}

Core content areas included medical care organization, healthcare economics, quantitative methods and health data analysis, technical methods for health system monitoring and operations, program evaluation, accounting and financial management, principles of health service management and strategic management, and Navy healthcare, an obviously useful topic, with a focus on Naval healthcare issues taught by staff from the Navy. The typical public health core courses, epidemiology, biostatistics, health behavior, and environmental health were also required as a component of the MPH.

An integrative management project was the capstone learning experience, required in lieu of a thesis, focusing on a specific problem or opportunity in the Navy unit where the student was employed (e.g., the preparation of a business plan, a strategic study, or a budget analysis). Students were to complete the integrated management study in five phases: identification of the problem or opportunity, proposal development and approval, study completion, report preparation, and study evaluation.

\section{PROGRAM MANAGEMENT AND EVALUATION}

Extensive marketing of the program was conducted internally to this Navy command and in other local military installations. A preliminary survey of potential students was performed to gauge potential interest in the program; the results were encouraging and reflected strong local interest.

To streamline the screening process, a preliminary application was required of all interested students; only those applicants deemed likely to meet the admissions criteria were encouraged to move forward to the full 
applications procedure. All students were reviewed by the same admissions committee and subject to the same admissions standards as on-campus applicants to the program. Program and career guidance was provided by the (two) Navy and (one) University faculty sponsors.

The instructors were subject to the University's evaluation protocols, which provided quantitative and qualitative assessments of course content and instruction. Students indicated a high level of satisfaction. Based on an overall composite score, all instructors combined received a quantitative total average teaching effectiveness rating of 3.4 (on a 1 to 4 scale, 4 being the highest). Many scored even higher. Extensive interaction with students by the program directors provided an avenue of communication for feedback and continuing quality improvement.

Perhaps the most important measure of success is the professional and career impact of the program. Of the 22 students completing the program, 5 were in a higher-level position following the completion of the program as compared to their status on entry. Conversely, a number of students already held very senior positions and at least informally indicated that the program's content enhanced their workplace performance.

\section{KEY ISSUES AND LESSONS LEARNED}

Cost was a major issue. Although the program was extremely well priced (approximately $\$ 14,000$ for the entire program, exclusive of books), and student demand for the program was strong, many students had financial pressures and concerns. The Navy's substantial in-kind contributions and student financial assistance were instrumental in enabling the effective out of pocket costs to be kept extremely affordable.

The program was jointly developed and managed, which was another reason for its success, as both organizations had a vested interest and shared goals. The Navy provided all marketing, administrative and classroom space, some classroom instruction, including two Navy program coordinators (both are physicians-one holds a doctoral degree in Education and at the start of the project the other was Director of Medical Education; both were adjunct professors in the program), and tuition assistance. The University provided overall coordination, admissions and enrollment services, and most instructors, who typically taught the same class on campus. All students were considered regularly matriculated students and the program was provided through the College of Extended Studies (CES) on a self supporting basis.

Another concern during implementation was scheduling. About one-third of the students were physicians with demanding clinical schedules, and others were in various clinical positions. Clinicians typically wanted classes that met late in the day while department administrators and others preferred mid-afternoon classes due to family considerations such as child care. Classes were held on base in late afternoons and on some weekends. Two courses were offered each semester for six consecutive semesters, three semesters per year, to allow students to complete the program over two full years of study. Only one cohort was accepted and all students matriculated and graduated together with a few exceptions for late entrants and student military deployments.

All involved had high expectations for the program from the start. Quality of classroom presentation, relevance of course content, logic of course sequencing, use of relevant examples, modern content, and electronic instructional support were especially appreciated. Group problem solving opportunities, interaction with instructors, and challenging assignments were also highly valued. Active duty students provided somewhat unique perspectives and experiences in classroom discussions, especially since several had been involved in providing healthcare services to both military and civilian casualties in combat situations. As part of infrastructure development efforts conducted by U.S. forces, one student had been given the responsibility of establishing healthcare systems for geographic regions of Iraq. The war significantly impacted the program, as many active duty students were sent on command missions, mostly to Iraq, Kuwait, and Afghanistan.

To accommodate these rotations, many instructors used podcasting, Blackboard, and other available distance-learning technologies to maintain attendance. Apple Computer, Inc. participated in the podcasting efforts through its federal systems division. Interestingly, bandwidth was workable for land-based deployments, although one student did report that he walked about two miles through the Iraqi desert looking for an available computer to take an exam! Students aboard ships had much more difficulty using these technologies; bandwidth priorities were 
limited for nonmilitary applications. It was necessary for some students to complete their requirements after deployments had ended.

Due to competing demands on student time, aggressive assistance and close monitoring of student progress in each course and in the program overall by faculty, staff, and administrators was a main component of the program's success. Those individuals not on deployment, as well as civilian and contractor employees of the Navy, were under tremendous workplace pressure owing to the loss of personnel to deployments, retirements, and the reality that all military facilities were "stretched thin" due to wartime commitments. NMC, moreover, has been impacted by increased workloads from war casualties. Students in a more traditional setting would likely have more flexibility and time for their studies.

Students in this cohort experienced a variety of work-related short-term assignments requiring travel that impacted their studies. In many instances the travel to temporary duty assignments, excluding actual deployments, lasted 7-14 days. In addition to frequent temporary assignments for both Navy co-directors of the program, one codirector was deployed for a number of months to Asia.

The University was very supportive and proud of the program. San Diego State has a very active veterans support and assistance effort. The widely known Joan and Art Barron Veterans Center on campus provides an array of support services to current active duty military personnel and to veterans. Various news releases involving the program provided an opportunity to highlight cooperation with the military, an important issue in a long time "Navy town." The school has other important ties with the Navy including current research, active duty sponsored students assigned full time for on-campus study, joint faculty appointments, and the University recruitment of a number of outstanding faculty from Naval retirements.

\section{CONCLUSIONS}

In summary, the health services management program described here provided an opportunity for a civilian program to contribute to U.S. military training needs. The strong support of Command leaders and committed Navy internal sponsorship was essential to the initial approval and eventual success of the program. Navy contributions to marketing, pricing, scheduling, educational technology, and space were also paramount to program success (Poss, Cupp, \& Williams, 2008).

Decreasing defense budgets and changing missions mandate that military and civilian personnel in managerial positions be trained to provide efficient programs. The military has always relied on outside sources of expertise for education and training. These relationships will likely become even more important in the future. Presenting and examining successful models for collaboration is highly valuable. At the same time, identifying limitations and challenges can be equally useful in assuring the success of collaborative ventures.

Now that some time has evolved since the completion of the program, $25 \%$ of the initially matriculating students have failed to complete the program, a key evaluative indicator. The reasons run the gambit from losing interest, to other demands on time, to rotation out of the service. Those with limited extenuating circumstances were accommodated but the inevitable passage of time also meant that the rules regarding the maximum time frame for program completion prohibit any further graduates. But nearly all of those not completing the program had faced a formidable set of unmet requirements. That most cohort members successfully completed the program, even in the face of many competing demands and challenges, is a testament to both the drive that these students exhibited and the commitment of the program to achieve student success.

And a final note: changing technology and the relatively early stages of fundamental changes in the education industry have increased the focus on lowering costs, shifting more education to on-line delivery modalities, and even redefining what constitutes a graduate education (Wendler et al., 2010). Perhaps the program discussed here was a precursor to these developments.

Students selected for this program had extensive prior clinical and managerial experience, were highly motivated, and were used to working extremely hard. The unexpected impact of war presented significant challenges 
to students and instructors alike. However, despite these obstacles, a high degree of satisfaction was ultimately accorded to this program. Clearly, civilian health services management programs can successfully partner with local military commands in providing high quality and cost effective management education to active duty and civilian personnel.

\section{AUTHOR INFORMATION}

Stephen J. Williams, Sc.D., is associate dean of the College of Health and Human Services at San Diego State University (SDSU). He was previously co-founder of the SDSU Graduate School of Public Health and founder of its program in health services administration (now Health Management and Policy), and co-developed the program described here. He was educated at Carnegie-Mellon, MIT, and Harvard. He is the author of over 130 professional publications including over twenty five academic and mass market books. He has previously been the principal investigator on approximately $\$ 2.5$ million of extramural grants and contracts. E-mail: swilliam@mail.sdsu.edu (Corresponding author)

W. Bradley Poss, M.D., is Professor of Pediatrics at the University of Utah, Medical Director of the Pediatric Intensive Care Unit at Primary Hospital, and Co-Director of the Pediatric Critical Care Fellowship Program. He completed his academic studies at the University of Kansas, a pediatric residency at the Naval Hospital Oakland, and a pediatric critical care fellowship at the University of Utah. He retired after 20 years in the US Navy where he served in a variety of leadership positions including Director of Graduate Medical Education and Chairman of the Department of Pediatrics at Naval Medical Center, San Diego. In addition, he served as an Amphibious Task Force Surgeon in support of Operation Enduring Freedom from 2001-2002 and as the THIRD Fleet Surgeon from 20052007.

Craig L. Cupp, M.D., Ed.D., is a private practice otolaryngologist and facial plastic and reconstructive surgeon. He is a fellow of the American Academy of Otolaryngology and the American Academy of Facial Plastic \& Reconstructive Surgery. Additionally, he holds a clinical faculty position at the University of California, San Diego. He received his medical degree from the University of Southern California and completed a residency at the Naval Medical Center, San Diego and a fellowship at the University of Washington. He has served as a physician and medical leader in the United States Navy including at Naval Medical Center, San Diego.

\section{REFERENCES}

1. Chaffee, M. W., \& Mills, M. E. (2001). Navy medicine: A healthcare leadership blueprint for the future. Military Medicine, 166(3), 240-247.

2. $\quad$ Christman, F. (1985). The romance of Balboa Park. San Diego, CA: San Diego Historical Society.

3. Naval Medical Center San Diego (NMCSD) (2013). About us. Retrieved from http://www.med.navy.mil/ sites/nmcsd/CommandInfo/Pages/AboutUs.aspx

4. Poss, B., Cupp, C. L., \& Williams, S. J. (2008). Executive management education in health care at a naval medical center: A descriptive report. Military Medicine, 173(2), 198-202.

5. Sentell, J. W., \& Finstuen, K. (1998). Executive skills 21: A forecast of leadership skills and associated competencies required by naval hospital administrators into the $21^{\text {st }}$ century. Military Medicine, 163(1), 38.

6. U.S. Navy Medicine. (2013). Navy medicine strategic map: Retrieved from http://www.med.navy.mil/ Pages/StrategicMap.aspx

7. Wendler, C., Bridgeman, B., Cline, F., Millett, C., Rock, J., Bell, N., \& McAllister, P. (2010). The path forward: The future of graduate education in the United States. Princeton, NJ: Educational Testing Service. 


\section{NOTES}

